(C2008 IEEE. Personal use of this material is permitted. However, permission to reprint/republish this material for advertising or promotional purposes or for creating new collective works for resale or redistribution to servers or lists, or to reuse any copyrighted component of this work in other works must be obtained from the IEEE. 


\title{
Supplier Intelligence In MRO Procurement
}

\author{
Dr Ananda Jeeva \\ Faculty of Business \& Informatics \\ Central Queensland University \\ Rockhampton, QLD 4700, Australia \\ Email: a.jeeva@cqu.edu.au
}

\begin{abstract}
This paper explores the requirements for long term sustainable procurement practices. In the procurement of very expensive plant and equipment, MRO and the very long term continued availability of parts and components is very critical. Sustainable procurement practices are also critical in the continued non-disruption of critical parts and components in a manufacturing process. It proposes that procurement personnel and practices must have appropriate information and data of their prime suppliers of critical components, sub-assemblies and parts. Current research and literature search indicates there is very little publication and research investigating supplier intelligence (SI) in the context of the suppliers' suppliers' financial health, corporate governance, operating environment, capability, capacity and basic long term survival. This paper proposes the need for a conceptual model for gathering supplier's suppliers' intelligence for long term supplier relationship management; negotiation and contract management. The impetus for such information of a trading partner is becoming more critical since the collapse of large multi national corporations. Supplier intelligence is a fitness evaluation that enables the buyer to operationalise their long term procurement strategies with more certainty and lower risk. This paper also proposes how long term contractual terms and conditions may be designed taking into consideration of supplier's suppliers' profile to build superior supply chains and increase competitive advantage, hence a sourcing strategy.
\end{abstract}

\section{Keywords - supplier intelligence; procurement; MRO;}

\section{INTRODUCTION}

In manufacturing and mining operations, the failure of plant and equipment may stop operations for hours or days. This stoppage can cause millions of dollars loss to companies. Hence, maintenance, repairs and operations (MRO) department need to maintain an inventory of spares in cases of emergency; and also purchase critical parts and components. Also the procurement department must know where and from which suppliers to purchase these spares.

Some of the expensive plant and equipment have a working life of 30 to 50 years, for example locomotives and longwall drillers. These plant and equipment need spare parts and components throughout their working life, and procurement personnel need to ensure that parts, components and after sales service are available for the duration of its working life.

These spare parts and components may be categorised as critical, essential and non-essential. For the efficient and effective manufacturing and mining operations, procurement plays a critical part in ensuring that parts and components are readily available or can be readily sourced when necessary.

Procurement personnel and activities may be faced with increased complexity in sourcing due to discontinuation of critical parts and components, new sources of supply, uncertainties in the environment, quality, capacity and capability of suppliers, supply configuration, corporate social responsibility, greening and contractual obligations. The main uncertainty is the untimely demise of suppliers' supplier.

This increase in complexity of procurement is making the supply chain less transparent, therefore less manageable. Further complications are shorter product life-cycle, demand spikes, changing customer expectations and new suppliers. Effective procurement strategies and solutions have to be used to reduce costs, improve efficiency, performance and to ensure that parts and components are still available after several years or even decades.

In the manufacturing sector, research [1] shows that only $11 \%$ of companies studied have any form of online transactional and information-sharing capability with their immediate suppliers. This research also showed that less than $1 \%$ of companies are actually capable of monitoring and measuring their online supplier performance.

Therefore, the intention of this paper is to increase the need for awareness and implementation of supplier intelligence database for competitive advantage by proposing a conceptual model of SI.

\section{DEFINITION}

There is much published literature on competitive intelligence and business intelligence but none on supplier intelligence. The definition stated here is borrowed from North Carolina State University.

Supplier Intelligence is the purposeful, coordinated and ethical monitoring of strategic suppliers, within a specific marketplace.

But this definition is insufficient and too narrow. It constraints itself narrowly within a specific marketplace. It is accepted that all supply chains transcend different market economies, industry sectors and geographical regions. This paper argues that various markets and influences affect each and every entity along a supply chain. 
Since every entity along the supply chain is in different market sectors and economic markets, there are different external environmental influences. Other influencing factors are geographical, political, legal, social, cultural, economic and technological. Any of these factors has the potential to affect the operations and production process of the entities along the supply chain.

The internal factors also affect the operations and production process. Internal factors could be finances, human resources, skill, expertise, technology, capability, capacity, etc.

Hence external and internal factors must be part of SI database, together with possible expected future trends. Therefore, supplier intelligence should be defined as the up to date knowledge base of critical suppliers incorporating the suppliers' market intelligence, business intelligence, competitive capability, financial stability including their suppliers' suppliers' intelligence in the very long term.

\section{NECESSITY FOR SUPPLIER INTELLIGENCE}

Manufacturing and mining operations cannot afford to come to a stand still or be disrupted due to lack of or delayed supply of critical parts, components or sub-assemblies for operational plant and equipment. Similarly with the attendance of specialised skilled service personnel for MRO.

The procurement department must always be ready with an inventory of the critical part or components; or at least know where to source that product or service in emergencies. SI is necessary to know that the supplier will provide this support for continued operations of the organisation.

Selecting the right supplier who will provide the required materials in a timely and effective manner is no longer a competitive advantage, it is a necessity. Competitive advantage of SI is to know and be more aware of the suppliers of critical parts and components, that they will always have the capability and capacity to continuously supply the products in the future.

Supplier Intelligence should provide the detailed knowledge of the supplier's internal and external environment. This environment includes the supplier's economic, political, legal, cultural, social and technological circumstances. Supplier intelligence should also include the financial stability of the supplier, market factors and information about the suppliers' suppliers.

Financial data should include capital investments, debt, share market performance, financial report methods, auditing, corporate governance, accounts receivable details, accounts payable details, etc. These data provide the financial intelligence whether that supplier can survive the next few years in a financial capacity. This financial intelligence and stability must be transparent whether the supplier is a public listed company or privately owned.

With the advent of corporate social responsibility and green procurement, Supplier Intelligence would be more critical in the future assessment of supplier suitability [2].
The relationship criteria and attributes of the supplier's suppliers are also of concern as it can cause a domino effect similar to the bull-whip effect. This is an extension of supplier selection attributes. A profile of the supplier must be created based on the above factors, in the SI database.

The long term survival of suppliers is directly related to the long term survival of the buyer. The buyer must have full knowledge of the suppliers' environment to ensure that the supply chain is not threatened. This information includes the supplier's industry and economic knowledge as well as old and new trends. Other factors are impact of technological advances within the supplier's domain and whether the supplier is in tune and aligned with technological advances.

The supplier and Supplier Intelligence may provide the buyer with knowledge to make short term and long term informed decisions. Decisions may include short term and long term contracts, terms and conditions within the contracts. Supplier environment information sourcing should include financial data, market data, operations and production information.

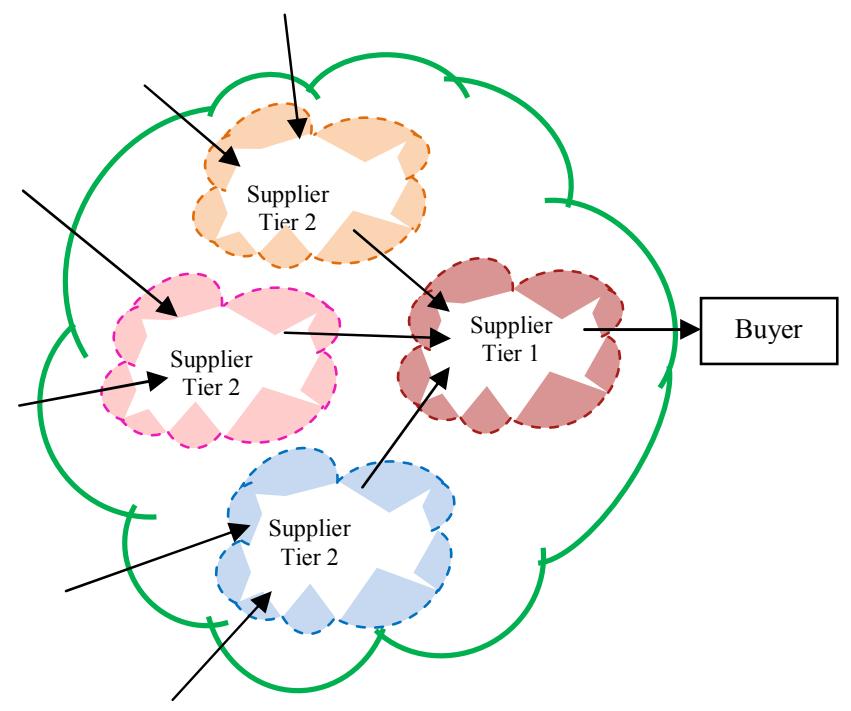

FIGURE 1

PURCHASING ENVIRONMENT

\section{BUSINESS \& MARKET INTELLIGENCE}

This paper promotes the idea that business intelligence is part of Supplier Intelligence. It includes information used in decision making process. If this business intelligence is available of the supplier and suppliers' suppliers' companies (Figure 1), then a much more accurate profile of the first and second tier suppliers may be established [3]. Business intelligence data may include:

Key performance indicators

Spend

Demand

Performance

Finance

Quality 
This paper also promotes that market intelligence is also part of Supplier Intelligence. Market intelligence provides information of the suppliers' external market conditions and environment. This market environment would be vastly different among each entity along the supply chain; and the influencing factors would be different as well.

Market intelligence would provide information on the suppliers' performance in that market sector such as market leadership, competitors, technological advances, suppliers' supplier, etc. Market intelligence data may include:

\section{Markets \\ Industries \\ Good \& commodities \\ Finance \\ Suppliers \\ Competitors \\ Technologies}

Market reports are part of market intelligence. It provides information on the suppliers' market, example: market share, players in that market, competition, financial data, research \& development, etc.

It also provides information on new developments and opportunities in that market and whether your suppliers are taking advantage of it and why not. This provides a clue to the decision making process of your suppliers and how that will affect your procurement activities in the short and long term. SI should include reasons, advantages, disadvantages and implications of decisions made by suppliers and their suppliers.

\section{ECONOMIC REVIEW}

An economic review provides a snap shot of the suppliers' country or regional status in terms of inflation, employment, exports, imports, GDP, GNP, balance of payments, current deficit, the role of governments and private sectors in the country's or regional development.

Economic factors affect all businesses in the country/region and in turn will affect the way businesses (suppliers) operate and behave. This will have long term implications for procurement activities, specifically contracts.

\section{FINANCIAL ACCOUNTING DATA}

Financial health evaluation of suppliers is very important. Initial screening process could eliminate many risks. Some publicly listed company data is readily available. If not, request at initial evaluation process.

A healthy financial condition will indicate if the supplier will survive in the long term, have necessary resources to invest in plant, equipment, research and development. It also prevents the supplier from becoming too dependent on the buyers for financial support. This may lead to a difficulty in switching suppliers.

Financial ratios also provide the health condition of companies. Financial ratios that should be included in the SI database are liquidity ratios, activity ratios, debt ratios, profitability ratios and market ratios.

This financial analysis must also consider the reasons for the poor financial condition. That supplier may be in the fore front of leading edge technological development.

Other financial and accounting information should include information on shareholders, debtors and creditors.

Financial liability may lead to a supplier being taken over by another company in acquisitions and mergers.

\section{MERGERS \& ACQUISITIONS}

The vulnerability of a supplier being taken over by acquisitions or merger is also a critical issue for purchasers. It is not known after the merger/acquisition if the new management will continue the production and supply of critical products to their buyers.

Supplier's suppliers must be evaluated if there are possibilities of takeovers in the near future. These takeovers and mergers may cause the disruption or discontinuation of critical spares and components.

If there are possibilities of take over, procurement personnel need to re-evaluate their strategies if the merger or takeover happens. They need to evaluate the pros and cons of the merger/takeover. How is it going to affect their activities in the short and long term?

Strategies may include switching suppliers, negotiating new contracts, terms and conditions.

\section{STOCK MARKET WATCH}

The performance of the suppliers' company on the stock market is a very good indication of the health of that supplier organisation. The stock prices movement of the stock prices over a period of time may provide clues as to the long term survival of the supplier. It may also be used to forecast trends.

Stock market watch also provides performance information of other suppliers in the same market. Procurement personnel need to observe and record the performance of these competitors. These competitors may become significant substitute suppliers in the future, if something was to happen to the current supplier.

A risk score matrix is proposed to be developed for each supplier and their competitor, based on their stock market performance. If the risk score of any supplier increases, procurement personnel would already have a profile of the competitors (alternate suppliers) if supplier switching is required.

\section{TRENDS WHICH INFLUENCE COMPETITIVE MEASURES}

Procurement practitioners need to be aware of common trends that influence competitiveness along the supply chain. Some of the common trends are customer sentiments, product life cycles, new product development, technological advances, new entrants to the supply base and cost drivers. 
Customer needs are increasingly more demanding and less loyal customers are likely to take their business elsewhere. Products with shorter life cycles require greater planning for supplier sources. New product development requires greater involvement of suppliers. Also wider product variations put greater pressure on production processes and inventory management.

SI should include appropriate data for decision making. This data need to be collected, collated and analysed for decision making in strategic procurement.

\section{COMPETITION, POLITICAL \& ECONOMIC FACTORS}

The behaviour and reactions of suppliers' suppliers based on the actions of their competitors is a concern. This reaction would indicate the stability or instability of the suppliers' suppliers. If the supplier is not affected then that supplier has a stable competitive position.

SI data must include their competitors' actions and strategies. This data must be updated periodically. It will provide an indication of possible threats to suppliers' suppliers.

Factors that affect the capacity and capability of suppliers in all tiers along a supply chain are: labour trends, unemployment, cost of fuel, land; political stability, tax environment, infrastructure - roads, rail, telecommunications, technology development; population growth, propensity for natural disasters, healthcare and terrorism. These factors must be included in the SI database.

\section{PRODUCT LIFE CYCLE}

Product life cycles have a direct relation on the sustainability of the MRO of expensive plant and machinery. Companies need to take an audit of which of the products, components or sub-assemblies are critical. An evaluation audit of the life cycle of all critical parts and components must be administered. What is the obsolescence rate? How much can be recycled, remanufactured and/or refurbished.

As products are manufactured, they go through a process of innovation for the next model. This innovation process and new product development may involve suppliers who also innovate and improve their parts, components and subassemblies. Therefore, the original product would be much different in attributes, price, design and configuration from later models. This could create a compatibility and/or unavailability of parts during the decline stage of the product life cycle stage. Therefore SI must ensure that exact replacement parts and components are available and are still procurable throughout the life span of the plant and machinery.

\section{COST DRIVERS FOR SUPPLIERS}

If the cost drivers of suppliers and their suppliers is known and understood, it will be easier to develop strategic relationships by working together to make those cost drivers work for the benefit of both the buyer and suppliers. This can lead to more productive long term relationships.
Some of the cost drivers are: lowest acquisition cost; lower total costs; quicker delivery; greater product innovation; higher customer satisfaction; higher competition and proliferation of new suppliers.

SI could include cost driver information for reducing the overall supply chain cost, as the future of competition has been promulgated as supply chain versus supply chain [4].

\section{SUPPLIER SELECTION CRITERIA}

One of the main applications of Supplier Intelligence should be in supplier selection. SI should provide sufficient knowledge to select or reject suppliers for critical and essential parts and components. It should also answer the following questions:

How well are the suppliers meeting the needs?

Do they really understand what is needed from them?

Is the effectiveness of the contracts maximised?

When it is time to renegotiate contracts, is there sufficient information to make the best deal?

What negotiation powers are there?

Is the supplier KPIs measured, such as on-time delivery, responsiveness to order changes, cost containment, purchase order accuracy?

Are the KPIs aligned with strategic corporate goals?

Are scorecards built for regular review with suppliers?

\section{SUPPLIER ATTRIBUTE EVALUATION}

Supplier attributes are part of supplier selection criteria and must be continuously updated as part of SI. They include quality, pricing delivery standards and lead times. Supplier management attributes include long range planning practices, CI, TQM, turnover, professional experience, vision, training \& development, suppliers' personnel capabilities - commitment to CI and TQM, skills \& ability, workforce flexibility, employee morale, turnover. Suppliers' corporate culture determines how the internal organisational culture is maintained and developed.

Suppliers' commitment to Total Quality Management, performance, systems and philosophy should be included in SI database. Suppliers' attitude and aptitude towards environmental regulation compliance and Corporate Social Responsibility may determine the future relationship, as there is a global push for environmental and 'greening'. Therefore, procurement personnel must embrace 'green procurement' and similarly select 'green' suppliers.

Suppliers' information systems capability management also determines how transparent the supply chain can be. This includes what, how and when information is shared among supply chain partners.

Suppliers' cost structure - suppliers' total cost including direct and indirect costs, operating costs and overhead costs provides an understanding of how efficiently a supplier can produce an item, and identifies areas for improvement. Process and technological capabilities -technology, design, methods and equipment are important. Other attributes are: Financial Capability and Stability; Production Scheduling and Control 
Systems; E-business Capability; Supplier sourcing strategies and policies; and long term relationship potential

\section{FUTURE MARKET REQUIREMENTS}

Supplier Intelligence should also include information about the future requirements of first and second tier suppliers and how they manage those requirements. The capability and capacity of suppliers' ability to manage future requirements is critical for the sustainability of strategic relations and strategic procurement from these suppliers.

Suppliers need to be future proofed. Supplier Intelligence data should indicate if suppliers have the capacity and capability to be futuristic. Part of being futuristic includes the ability to handle and manage global logistics demands, regional market requirements, regional demand forecasts and new product introduction.

\section{LONG TERM SUPPLIER RELATIONSHIP MANAGEMENT}

The SI database must also include answers to such questions like: Has the supplier indicated or committed to long term partnership arrangement? Willingness to commit resources in the relationship? Genuine interest in joint problem solving? Commitment to processes inherent in strategic relationships? Free and open exchange of information? Willingness to share in future planning? Willingness to commit capacity exclusively to needs of the long term?

Supplier Intelligence data also provides a platform for greater strategic relationships between buyers and suppliers. Supplier Relationship Management strategies should be formulated based on Supplier Intelligence. It needs to have information on factors like: How close the relationship should be? How strong should the relationship be? How long term should it be?

Supplier Intelligence should also provide information on strategic alliance of preferred suppliers at the least. With whom do your suppliers have alliances? How strong is it? How long has it been? How does that relationship affect the relationship with your company? What is the impact on your company if it turns bad?

\section{INFORMATION \& KNOWLEDGE MANAGEMENT}

Collection of Supplier Intelligence, market intelligence, competitor intelligence and business intelligence exists as unstructured data in the vast majority of organisations. These unstructured information exists in all office documents and communications.

The problem is how to combine and make use of these unstructured data into a coherent structured format that may be housed in a data warehouse. This data must then be collated and synthesised to be useful in decision making. Most of these data are poorly written, some out of date and some current. Good document management systems are necessary to exploit SI.
XVIII. PROCUREMENT PRODUCT CLASSIFICATION

Procured components, parts and sub-assemblies may be classified as pure product categories or under risk level or sourcing difficulty or other appropriate category.

This categorisation must be easily identified not only with procurement staff but also with end user staff in the organisation. This paper proposes that most parts, components and sub-assemblies may be classified as critical, essential, nonessential and vulnerable.

Critical Without this part or component, operations will become crippled, causing the company millions of dollars.

Essential Without this part or component, operations will be severely affected. Operations may be less effective and efficient causing much delay and wastage.

Non essential All other parts and components that are required for the daily operations, but can wait for a few days/weeks for replacement.

Vulnerability It is also recommended that the procurement team categorise specific parts and components as vulnerable, according to current availability, sourcing difficulty, future production and availability, alternate suppliers, future prospective suppliers and pricing. A Risk Scoring method is proposed.

\section{RISK SCORING}

A Risk Scoring matrix that may be used to score the supply of critical and essential parts, components and sub-assemblies. This risk scoring must be updated every so often. There should be two risk score matrix. One for the supplier and the other for the product (part, component and sub-assembly).

Products may be grouped into categories as critical, essential and non essential. This may then be sub categorised into main supplier and minor suppliers. The suppliers may be grouped by their capability and capacity attributes.

The Risk Scoring matrix may then be designed as per category/product sorted by suppliers. Thus, providing a Risk Scoring on products as well as suppliers and their suppliers.

XX. TAXONOMY OF RISK MATRIX ATTRIBUTES

Examples of risk matrix attributes may be:

Continued supply capability

Quality \& Quantity

Technology competence \& leadership

Financial situation

Price competitiveness

Location risk \& Shipping mode

Competitive factors

External factors influencing suppliers

Internal factors influencing suppliers

Long term capacity and capability utilisation

Long term pricing factors

Total cost of commodity

Technology breakthroughs

Lean manufacturing opportunities 
Data to synthesize production costs

Productivity initiatives

Product life cycle

\section{PROCUREMENT OF SERVICES}

Specialised services are another critical factor in manufacturing and mining operations. Many organisations out source much of their services. Procurement of services may be as complex as product sourcing. Services are intangible. It is difficult to measure services performance quantitatively. However, an attribute score card may be used for services procured in the past, present and the future to create a probability risk score.

The intangible attributes of services may require a probability scenario matrix, which may be created for these outsourced services. This will allow procurement professionals to always have an alternative supplier of services.

If there are contractual obligations with select service providers like telecommunications, contractual negotiations must be made as to the lag/lead time of service personnel to attend the site.

\section{PROCUREMENT CONTRACT \& NEGOTIATIONS}

Factors that affect negotiations are many. Here this paper looks at Supplier Intelligence information that may influence the terms and conditions of long term contracts.

Some plant and equipment have very long operational life. Hence spares parts, components and sub-assemblies will be required for that life span of that plant and equipment.

In mining operations some of these plant and equipment are used underground and never see daylight, but they are essential to mine operations and profitability.

Even if these plant and equipment may be later sold, for them to have a substantial depreciated or salvage value and a useful operational life, spare parts and components must be readily available.

Purchasing contracts which stipulate after sales service and availability of service expertise, parts and components need better negotiating terms.

Greater negotiating power is obtained when there is knowledge of the first and second tier suppliers' capability, capacity, strengths and weaknesses. Hence, long term variations may be included in the terms and conditions of the contract [5]. Supplier Intelligence provides much data for negotiation power. The more knowledge procurement personnel have the more power they wield [6].
XXIII. TRADE OFFS

Procurement practitioners must also be aware of the constraints and limitations of the amount of trade-offs they are willing to sacrifice to collect and maintain the SI database.

\section{STRATEGIC PROCUREMENT}

Strategic procurement can help maintain and increase an organisation's competitive advantage in a variety of ways. First, it provides certainty so that long term plans and strategies may be planned and implemented. Secondly, it reduces the risk factors. Third, it provides knowledge on supply trends. Fourth, it enhances the existing relationship between supplier and purchaser. Fifth, it improves supplier service levels and delivery performance [7].

\section{FUTURE IMPLICATIONS}

The advent of Corporate Social Responsibility and environmental concerns together with the ramifications of antiterrorism laws, organisations now and in the future must be more accountable and responsible in their procurement activities. They need to know from whom they procure and sell their products to.

This includes the origins of parts, components and subassembles and where the finished product is finally consumed and by whom. Although it is very difficult for organisations to ensure that their finished product does not land in the hands of terrorist organisations, organisations have to be vigilant about the origins of raw materials, parts and components they procure.

The sooner a concerted SI database is established, the more efficient and effective it is to comply with future legal and community pressures.

[1] Gartner Consulting 2006

\section{REFERENCES}

2] S. Case, "Strategies balance cost, human health and environmental concerns", Government Procurement, February 2005.

[3] H.J. Watson and B.H. Wixsom, "The Current State of Business Intelligence", Computer, Vol. 40/9, 2007

[4] D.M. Lambert and M.C. Cooper, "Issues in Supply Chain Management", Industrial Marketing Management, Vol.29/1, 2000.

[5] L.L. Thompson, 2004, "The Mind and Heart of the Negotiator", $3^{\text {rd }} \mathrm{Ed}$, Pearson Prentice Hall, New Jersey.

[6] M. Buelens and D.V. Poucke, "Determinants of a negotiator's opening offer", Journal of Business and Psychology, Vol. 19/1, Fall 2004.

[7] S. Rajagopal and K.N. Bernard, "Strategic procurement and competitive advantage", International Journal of Purchasing and Materials Management, Vol. 29/4, 1993. 